\title{
A Supply Chain Model for Library Quality and Service Improvement
}

\author{
Nancy Kress \\ North Carolina State University \\ nancy_kress@ncsu.edu \\ Joel Wisner \\ University of Nevada, Las Vegas \\ Joel.Wisner@unlv.edu
}

\begin{abstract}
The key to a library's success is its ability to effectively and economically deliver services and information that users value. Additionally, the objective of supply chain management is to coordinate the focal firm's processes and activities with those of its suppliers and customers, such that the firm's delivered products and services meet or exceed customer requirements. It thus seemed appropriate to analyze a library from a supply chain perspective to assess and improve its ability to serve its users. Consequently, the authors employed an action research methodology to work with library personnel from two departments, User Services and Technical Services, as they merged into one division, to map the information resources supply chain of the University of Nevada, Las Vegas Lied Library. Once the supply chain model was completed, key processes were analyzed and performance measures designed, with the goal of improving division products and services. This paper reviews the relevant literature, presents the Lied Library information resources supply chain model, and provides the performance measures along with several improvement examples.
\end{abstract}

Keywords: supply chain, library, service improvement, performance measurement, action research. 


\section{INTRODUCTION}

Operating in an environment of shrinking operating budgets, cheaper and faster computing capabilities, and more users demanding a wider range of library services, library administrators at most universities are struggling to deliver the many and often changing products, services and information items their customers seek. Simply phrased, libraries today are learning to do more with less. Consequently, libraries are considering new ways of managing work. Scarce resources in many cases call for radical solutions that can include a restructuring of the conventional vertical organization. Library success and viability also depend on management's ability to coordinate the network of relationships and processes linking the library's internal and external supply chain members to provide the desired services.

Similar to profit-making enterprises, the key to a university library's sustainable effectiveness lies in delivering high quality products, services and information which satisfy customers (Christopher, 1998). Management needs to understand what library users require, as well as the processes transforming information content into valued information resources and associated services.One strategy for improving library quality is the practice of supply chain management. It offers the advantages of extensive cooperation between suppliers, internal organization units, and customers. Over the past twenty years, supply chain management research and practice have provided a successful set of tools for organizations seeking to reduce costs while improving quality and customer service.

This paper presents an action research study, demonstrating the use of supply chain management methods to merge functional departments and to improve processes that deliver value to library users. Action research is rooted in the social sciences and is a type of empirical research wherein participants in the study are empowered to improve the practices under investigation; they are knowing, active members of the research-in-progress. Action research can be guided by professional researchers, with the aim of improving knowledge within the work environment of the study. Researchers collaborate with stakeholders in data collection and inquiry to ultimately identify new courses of action (see for example Finn, 1994 and Reason and Bradbury, 2001). This study involved two merging departments at the University of Nevada, Las Vegas Lied Library-their functions were analyzed in their entirety as a starting point for improving the overall effectiveness of the library's information supply chain.

While many similar definitions of supply chain management (SCM) exist, Lambert, Cooper, and Pagh(1998) perhaps explained it best:

\begin{abstract}
Supply chain management is the integration of key business processes from end user to original suppliers that provides products, services, and information that add value for customers and other stakeholders.
\end{abstract}

The large number of existing supply chain management articles covering many industries indicate that it is a broad set of activities encompassing internal functional personnel, managers, and external supply chain members, involved in various process integration efforts. The basic objective of SCM is to provide benefits to supply chain members by offering better customer service, pricing, and quality to customers. In their empirical study for instance, Speckman et al. (1998) found the general objectives of SCM were to improve end customer satisfaction and supply chain member profits, while reducing overall costs. Over the years a number of researchers have found correlations between SCM success and the reduction of waste, continuous process improvement and the synchronization of material flows along the supply chain (see for instance MacDuffie and Helper, 1997; Christopher and Towill, 2000; Cagliano, Caniato and Spina , 2006; and Brondo and Baba, 2010).

The term, supply chain, has also been applied to libraries. Cornish (1996) made a very early reference to the information supply chain - he expressed the need for libraries and intellectual property owners to work together to improve information flow to meet the needs of users. Ball and Wright (2000) and Ball (2004) also referred to the information supply chain, describing the primary library supply chain processes as creation, publication, aggregation, access and use. Libraries were identified as intermediaries, supporting the aggregation, access and use functions.

Discussions and empirical analyses of library supply chains remains quite limited. Consequently, the purpose of this paper was to map a library information resources supply chain using the Lied Library 
at the University of Nevada, Las Vegas as a model. Further objectives were to use this model-building exercise as a way for merging department personnel in a unified manner, and as an analysis tool for evaluating and improving the ability of the Lied Library to provide the desired products, services and information to its varied customer base. Discussions of the applicable supply chain management literature, the methodology used, the Lied Library's information supply chain, the performance measures utilized, and number of supply chain assessments follow, including implications for library management and conclusions.

\section{LITERATURE REVIEW}

The study of supply chain management has become very popular in recent years as evidenced by the thousands of publications in both academic and practitioner journals and the initiation of numerous university and professional development programs regarding the topic. Most of the publications have dealt with various manufacturing industries such as automobile and electronics, while a much smaller number have concentrated on services. Even fewer have looked at library services in a supply chain context. The manufacturing and services SCM literature is briefly discussed first, followed by a look at the library SCM literature.

\subsection{THE MANUFACTURING AND SERVICES SUPPLY CHAIN MANAGEMENT LITERATURE}

Development of supply chain models began in the late 1980s as firms moved away from vertically integrated structures toward more outsourcing (Lummus and Vokurka, 1999). Consequently, managers realized there were certain benefits that could be attained through greater collaborations with these suppliers. With faster information sharing using electronic data interchange and point of sale systems, suppliers were able to forecast demand more accurately, improve planning, shorten lead times, and reduce inventories, while also reducing overall costs.

The SCM philosophy expanded the traditional internally focused integrating activities of logistics (Kahn and Mentzer, 1996), by bringing trading partners along the supply chain together with the common goals of efficiency, quality, and end-customer satisfaction (Harwick, 1997). Use of preferred sup- pliers (those with a desire and ability to support the strategic initiatives of the buying organization) was identified as one of the important early SCM strategies (Halley and Nollet, 2002).

Successful supply chains manage inventories through close relationships with material suppliers, and distribution and delivery services. A recognized goal is to replace inventory with frequent communication and sophisticated information systems to create lean systems, visibility, and coordination, so that merchandise can be replenished quickly and arrive where and when it is needed in smaller lot sizes (Handfield, 1994; Shapiro, Singhal, and Wagner, 1993). Frequent and accurate sales, production, and demand forecast information are transferred among members of a supply chain to counteract the distortion of information (also referred to as the bullwhip effect) as it passes back up the supply chain from the end-customer (Metters, 1997).

Fawcett and Magnan (1998) found several key characteristics of successfully integrated supply chains, including:

- A relentless focus on the customer

- Recognition that collaboration between firms is critical

- Concentration on processes instead of functions

- Seeing open communication as imperative

- Considering people in all decisions

- Making the investment in information technology, and

- An overriding concern for performance measurement.

A more recent trend is the study of service operations and their supply chains. Service organizations are members of supply chains, and include logistics and consulting services, insurers, banks, wholesalers, and retailers. Services can be suppliers to manufacturers, to other services, or to consumers. 
One challenge associated with service supply chains is the complexity of the supply chain itself. Spens and Bask (2002) for example, found the supply chain network for a blood bank to be extremely complicated, with many levels and components that had to be considered simultaneously. Other studies have compared service and manufacturing supply chains. Fearon and Leenders (1996) for instance, concluded that supply managers, whether employed by manufacturing or service organizations, were performing many of the same tasks such as purchasing, evaluation of proposals and supplier analysis. However, Smeltzer and Ogden (2002) found the complexity of purchasing services to be greater than that for purchasing materials due to the intangibility of the services and the difficulty of assessing financial and other benefits of the purchase. Finally, Krause and Scannell (2002) studied supplier development practices for manufacturers and service firms and concluded there were differences among the two types of firms. Service firms rated the importance of reduced cost, increased supplier responsiveness and improved delivery significantly higher. They also placed more emphasis on financial strength of suppliers when assessing their strategic goals.

Research has also focused on collaboration between services in supply chains. Frankel et al. (2002) for example, examined collaboration among supply chain members based on a study of 29 firms in the retail grocery industry. They found five common themes important to collaboration in a supply chain, namely:

- A willingness to make changes and be innovative

- An understanding of each supply chain partner's business

- Commonality in goals and objectives

- Application of appropriate performance measures and rewards, and

- The sharing of information.

Stank et al. (2003) looked at both internal and external collaboration. In a study of over 300 manufacturing and service firms, internal collaboration was found to improve logistical effectiveness in the supply chain while external collaboration influenced improvements in internal collaboration; the best firms were found to practice both.

\subsection{THE LIBRARY SUPPLY CHAIN MANAGE- MENT LITERATURE}

Regarding libraries, SCM research has been quite limited. Deriving from knowledge management theory, Katsirikou (2003) proposed a library supply chain model consisting of four integrated parts: the first part were knowledge resources such as publishers and database providers, digital media and research providers; the second part were the libraries' knowledge content and systems; this was then distributed to the libraries' members (the third part) who then acted as wholesalers to the fourth partthe library users. Pathak and Pathak (2010) applied Porter's value chain model to higher education as a service institution. They explained that shifts in higher education called for effective cost control to maximize customer value. They identified several drivers for managing higher education as a business. One driver, technology, has greatly affected how users navigate through information resource offerings. One quote by Pathak and Pathak describes the impact of technologies as information delivery changes from:

\footnotetext{
“... a high-contact, low-equipment service to a relatively low-contact, equipment-based service, where the moment-of-truth experience (the interface between the customer (student) and the frontline staff (teacher) may no longer be the focal point of value creation."
}

Cho (2010) recommended supply chain performance measures as an evaluation system for resource sharing in a Korean academic library. She noted that resource sharing and traditional supply chains were similar in their use of information technology, standardization, and integration of all participants. Performance could be optimized by emphasizing the importance of improving user satisfaction across all locations in the supply chain.

Applications of the supply chain model for libraries are also very limited. Li (2006) argued that libraries should do as any business does: satisfy its customers. As customers' need change, then library services must also evolve. The Cornell University library and the changes it underwent were used as a cen- 
terpiece of Li's discussion. Challenges to providing value to Cornell library customers were outreach activities and the building of staff skills to include expertise in use of emerging technologies, financial analysis, business modeling, and logistics and operational control. Meng-Xing, Chun-Xiao and Yong (2010) diagramed a supply chain for digital libraries composed of content suppliers, digital library alliances, content service providers, third-party service contractors and finally the library users. The authors presented the model as a response to the challenges presented by the culture of Google-style search engines.

A large research project on the impact of the digital publishing revolution in Australia is described in a series examining technology and the production of books. Cope (2001a, b) examined how technology affected the book production supply chain and the academic textbook supply chain. Particularly relevant to the internal library supply chain are how processes are affected as the Internet becomes a key tool in production and sale of information. The author also described how the "direction of change in the supply chain is disintermediation: the collapse of one element of the process into another, or the disappearance of one step." An issue for libraries in this era of changing formats is the delivery of electronic products alone or in combination with printed versions. Cope also noted that the role of the research institution is in developing opportunities for the information supply chain as the "resolution of the digital rights management issues can best occur in a highly complex environment (i.e. in terms of granularised texts, mixed formats, copying practices and so on)".

Indeed, technologies have tended to play key roles in the library research. Curran and Porter (2007) for example, described the use of radio frequency identification (RFID) tags and readers in library systems to reduce costs and improve library service quality. Heinrich and LaFollette (2010) described the use of an integrated library system at the California State University Northridge library and the impact of the system on vendor relations, workflows, customer service and costs.

A supply chain model can assist in delivering value for library users at a reduced cost through the integration of services. Thus, SCM can aid in meeting the personalized requirements of library users, while using lean systems to make efficient use of scarce economic resources for libraries as content providers. The methodology for this research is presented in the next section, followed by the UNLV Lied Library's supply chain, a discussion of the performance measures used to evaluate the library's ability to provide products, services, and information, and finally the conclusions.

\section{METHODOLOGY FOR DEVELOPING THE LIED LIBRARY SUPPLY CHAIN}

In 2009, the revenue projections for the state of $\mathrm{Ne}$ vada were grim, leading to a budget shortfall which impacted funding for the University of Nevada, Las Vegas (UNLV), and consequently its library. Library management decided a reorganization of two library departments, User Services and Technical Services, was necessary to cope with impending personnel layoffs. The resulting new division would operate with one division manager, which would be difficult unless a different management system was designed and employed.

This paper employed an action research methodology to create a collaborative environment wherein the division manager, department personnel, and a UNLV professor of supply chain management could create a working organizational model deemed acceptable by the members of the new division. The methodology was employed in part to allow new staff relations to form into a cohesive group working toward a unified goal. Most of the staff had never before been involved in reorganization efforts and were apprehensive about a new structure for the division. It was hoped that the collaborative environment and model-building effort would allow staff to develop trust in the new, resulting structure. Additionally, the collaborators sought to model the functions of the combined departments such that staff could understand the flow of information resources from the suppliers, through library processes, and finally to the library users. Knowledge of information resource flow would then ultimately be used to assess and improve the library supply chain's performance.

Supply chain management tools were selected since their objective is to integrate key processes from order to delivery, including purchasing, ordering, information processing, and storage activities to improve quality and customer service. As the purpose of the library reorganization was to improve the ability of these units to efficiently meet user re- 
quirements, SCM enabled the development of performance measurement systems concentrated on meeting customer requirements.

To begin, it was necessary to develop a beginning-toend understanding of the acquisition and delivery of information resources, to identify potential areas for cost-cutting or service improvement.The SCM professor was invited to work with the affected library division to develop a common understanding of internal and external supply chains, lean systems, and performance measures, and how these might be applied to the Lied Library.

Over the course a number of months in 2010 and 2011, a series of lively, interactive meetings were held between library management, key library personnel, and the authors to map a supply chain model, with the Lied Library as the focal member. The authors utilized a combination of lecture, interview, and Socratic method to first develop an understanding of SCM, and then to model the library's information supply chain. Initially, the active participant group struggled to identify and understand the handoffs between the selection and purchasing of information resources and the many processes of transforming these into what the library users required. Eventually, the internal value stream for the information resources supply chain emerged. Once the key value-creating processes were identified and mapped, it was possible to begin thinking of how to assess current performance and begin to find ways to improve that performance. Towards the end of the action research period, a series of meetings took place to focus on a compatible set of objectives based on user requirements and to reach consensus on the relevant performance criteria. A final set of meetings were held late in 2011 to discuss actual process performance and reach a consensus regarding process improvement techniques. The development of the Lied Library supply chain model is discussed next.

\section{THE LIED LIBRARY SUPPLY CHAIN}

The general Lied Library supply chain had to be identified before the information resources supply chain could be diagramed. Division staff referred to the supply chain models in the extant research to aid in this effort. Generally speaking, the Lied Library supply chain consists of processes which link the many library customers back up the supply chain to the various library suppliers. These processes are: the creation of information resources, building the collections, providing access to the collections via the catalog and website, and finally delivery of information resources and services to library customers.

Referring to Figure 1, the Lied Library's supply chain has three broad categories. The supply chain shown in the figure starts with the collection suppliers, who create information content, and the operation suppliers who provide products and services necessary for the library enterprise. The core of the supply chain is the library itself, where content is organized, stored and managed. The final entities of the supply chain are the users and the resource-sharing partners, who will ultimately make use of the content.

Figure 1. Lied Library supply chain

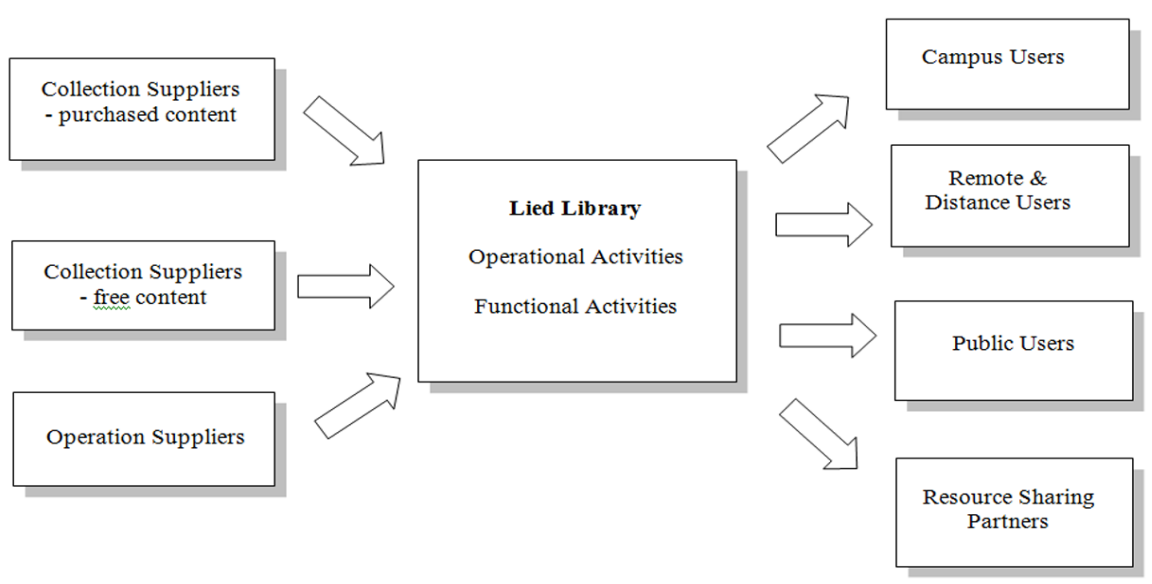




\subsection{SUPPLIERS}

The primary suppliers to the library are content suppliers, which include authors, publishers, serials subscription agents and database vendors. Libraries also occasionally receive collections at low or no cost, which include government documents, gifts, and an increasing number of free digital collections. The variety and different combinations of collection offerings run into the hundreds of thousands, creating the many choices necessary for meeting the needs of a large variety of library customers. The library must choose suppliers across multiple tiers to guarantee the availability of resources in the formats desired by customers. Suppliers are selected for their ability to bundle resources, which reduces cost, and also in cases where there is only one supplier offering a particular resource. Operation suppliers include those offering information architecture services such as library online public access catalogs (OPAC) and discovery platforms, which provide one simple search interface for a wide range of library resources. The Lied Library also requires equipment, furniture, office supplies and janitorial, maintenance and shipping services, which are purchased from operation suppliers.

\subsection{LIBRARY PRODUCTS AND SERVICES}

The Lied Library is shown as the focal member of the supply chain. Within the Lied Library are library operational and functional activities, which collectively are the library's internal supply chain. The internal library supply chain begins with identifying and selecting content and operations suppliers, purchasing products, scheduling deliveries, and receiving the products. Collection development is responsible for most of the selection and purchase of resources, although increasingly, library patrons are also driving collection purchases in the form of patron-driven acquisitions. Purchased resources are received by the library, to be delivered to the customer. Delivery includes all the steps necessary for receiving and storing orders. Receiving and storage activities involve record loading, shelving and storage (this includes traditional book stacks and storage facilities like automated storage and retrieval systems (ASRS), physical processing (which includes preservation and conservation), and knowledge base maintenance.

Within this SCM framework, the Lied Library serves essentially as a large semi-automated information hub and distribution center. Electronic information is stored as collections and accessed from servers, databases and information repositories. Record creation involves cataloging, digital collection creation, and institutional repositories. Services include reference and research support, library instruction, and access and delivery functions such as interlibrary loan, which represents a blend of product and service. The final element of the internal supply chain is the returns. A library return is generated when customers borrow physical materials from the library and then return them for re-shelving. Interlibrary loan and deselecting activities can also be counted as returns. Other activities provide the necessary support for the library's primary activities. These activities include providing technology, human resources management, customer support, collection management, preservation, and security.

Most libraries are organized by function and can be characterized by the traditional organizational chart. The basic functional areas of the academic library and the units contained within are:

- Collections - selection, reference, instruction, bibliographers

- Technical services - acquisitions, cataloging, ordering and receiving, electronic resource management

- Access and user services - circulation, interlibrary loan, reserve, book stacks

- Information technology and web services - integrated library systems (ILS), online public access catalog (OPAC), web and digital library services

When managers view organizations vertically and functionally, they tend to also be managed vertically and functionally. A silo effect can be created when internal units are managed independently, limiting interdepartmental communication and coordination. Conversely, managing an organization's internal supply chain in an integrated fashion creates an efficient horizontal flow of products and services while maintaining the administrative aspects of the hierarchy, thus eliminating any silo effect. Ideally, internal customers find they get what they want more quickly as well. Figure 2 represents the basic library operational and functional activities, arranged in a general supply chain sequence. 
Figure 2. Library operational and functional activities

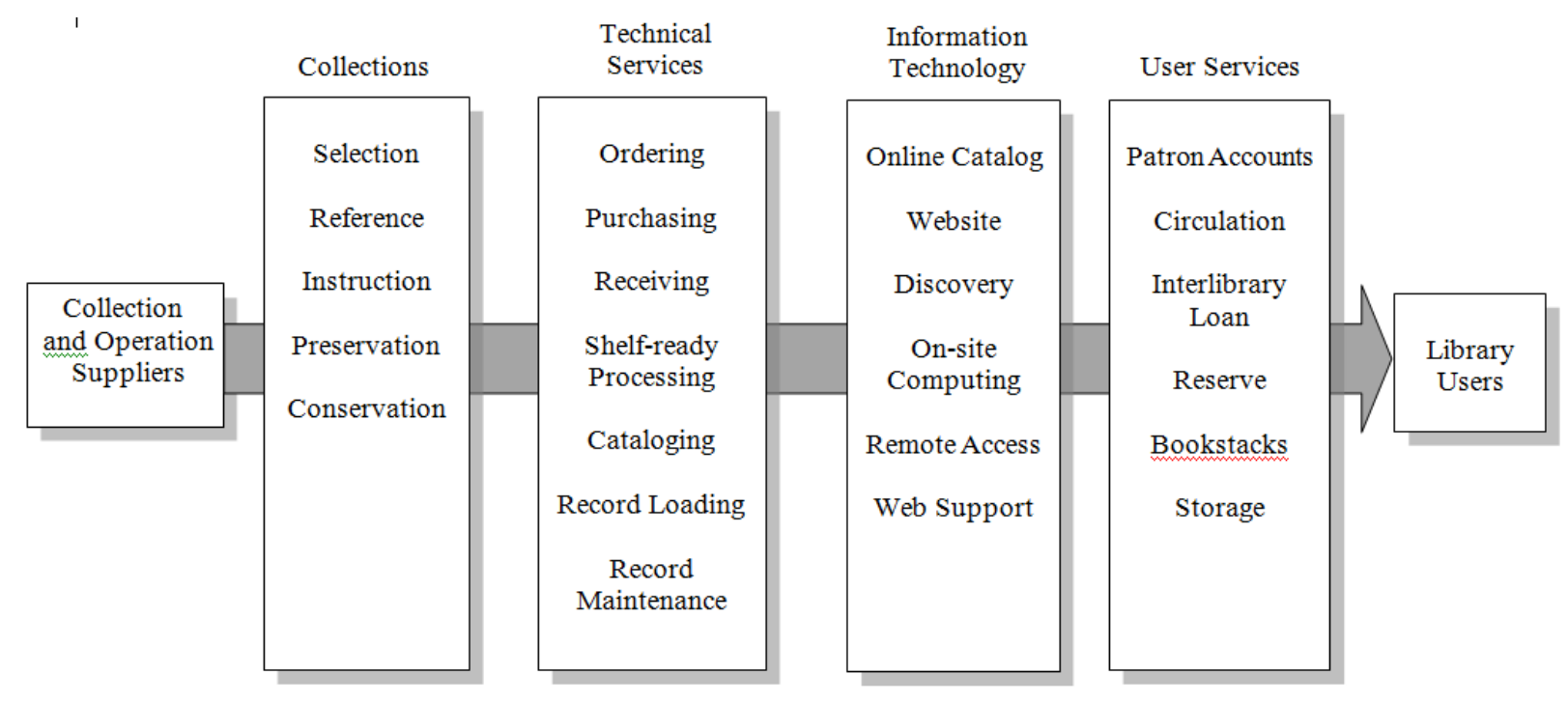

\subsection{CUSTOMERS}

Ultimately, the library supply chain extends to its customers. The core customers of academic libraries are the campus users, which include students and faculty. The libraries also typically serve remote and distance users as part of the campus community. For example, in addition to the main UNLV campus, there are several satellite campuses in Las Vegas, as well as a campus in Singapore for the study of hotel administration. As a public institution, UNLV shares its library's collections with seven other customer groupsuniversities and colleges in the Nevada System of Higher Education. The Lied Library also serves the Las Vegas community, providing access and limited privileges to the general public. Finally, the Lied Library expands the amount of available information resources it offers through resource sharing partners, which are known to most users as interlibrary loan.

\section{ASSESSING VALUE IN THE LIED LIBRARY SUPPLY CHAIN}

Value is created when a product or service meets the customer's requirements for time and cost, as defined by the customer. The value stream is thus the set of all activities bringing products and services to the customer (Womack and Jones, 2003). In the context of a traditional manufacturing firm, a prod- uct gains value as it passes along various horizontal production streams within the firm's internal supply chain and then is delivered (on time) to customers via some form of distribution system. In a library context, the primary activities associated with the creation and delivery of information resources and associated services within the library can be considered the value stream associated with the library's internal supply chain.

The Lied Library merged Technical Services with portions of User Services into one division-Logistics and Resource Distribution Services, to decrease staff costs and potentially increase end-user value. In the library, most of the workflow to select, acquire, organize and deliver information resources spans several departments and even divisions, moving horizontally across the organization. Looking beyond what were formerly department and division lines, the entire set of activities that create and produce information resources within the new division were identified from beginning to end and diagramed as the value stream. The division value stream is shown in Figure 3. 
Figure 3. Information resources value stream

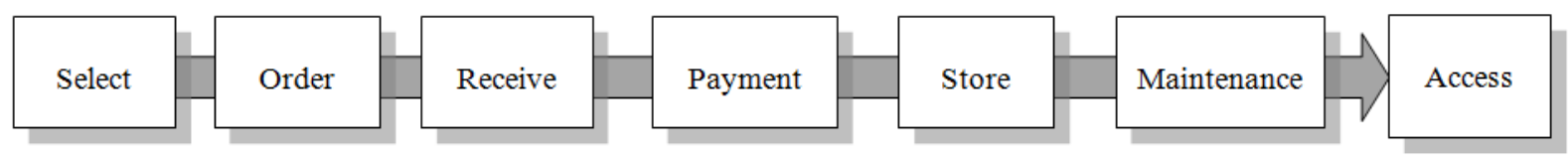

As mentioned earlier, the objective of value creation is customer satisfaction. For continuous improvement and customer satisfaction purposes, it was important to assess the performance of processes along the Lied Library supply chain. Libraries have traditionally focused on simple performance measures such as numbers of staff, size of collection, and expenditures, which can be compared across institutions. The economic challenges faced by higher education in recent years however, have resulted in a need for outcome-based measures that demonstrate relevancy to customers and stakeholders. Library leaders increasingly advocate for improved assessment, to ensure libraries "stay viable and true to their mandates of ensuring equitable access to information and delivery of services that are needed by library users and citizens" (Lakos and Phipps, 2004). Indeed, both the Association of Research Libraries and the International Federation of Library Associations have addressed the need for new measures describing how libraries fulfill their purpose (see Association of Research Libraries; Boekhorst, 1995). Supply chain performance measures can bridge this gap by evaluating the ability of library products and services to meet the needs of its users. Typically, firms employing supply chain management use a suite of supplier-, internal process-, and customeroriented performance measures for assessment and improvement purposes.

The first step in effective value creation is to identify the key performance requirements of the end-users. Leading up to the ultimate customer (the library enduser), each upstream part of the supply chain also has a customer. Since each customer tends to define value differently, it is important to translate the ultimate or end-customer needs into product and service requirements at each stage of the supply chain. These requirements are then translated into measurable performance indicators. Their primary purpose is to inform management of process performance, support strategic decision-making, identify problem areas, and set improvement targets. Ideally, the appropriate measures will clearly connect process performance to one or more customer requirements.
The required process performance will eventually be translated into purchasing requirements for the firm's suppliers, and in this way, processes become integrated along the firm's supply chain.

The new division's staff applied the supply chain model to issues as they arose throughout the series of active research meetings. The desire was to have staff focus on the customer view, rather than focusing on merely collecting numbers. By collaborating to resolve individual cases, staff began the transition from a transaction mentality to a customer relationship mentality. In the following sections, relevant performance metrics are presented and discussed for the information resources supply chain. They are grouped into three categories: supplier-focused, customer-focused, and internally-focused metrics. Some general issues of performance measurement for each category will be discussed, and key performance metrics will be introduced. Table 1 presents these performance categories and metrics.

To aid in the understanding of applying supply chain measures in a library environment, three Lied Library examples are presented below. One measure each is selected from the supplier, internal, and customer performance categories in Table 1. While the specifics in each case may be unique to the Lied Library, the measures still should prove broad enough to be applicable to most academic libraries. 
Kress, N., Wisner, J.: A Supply Chain Model for Library Quality and Service Improvement

Table 1-Information resourcessupply chain performance measures

Performance Category

Measures

\section{SUPPLIER}

\begin{tabular}{ll}
\hline Joumal/Database cost & - Avg. (actual cost per use) - (target cost per use) \\
$\begin{array}{l}\text { Vendor willingness to } \\
\text { negotiate cost or terms }\end{array}$ & - Avg. willingness scale: $1=$ unwilling, $2=$ indifferent, 3 = willing \\
$\begin{array}{l}\text { Quality of information } \\
\text { resources }\end{array}$ & - Avg. content scale: $1=$ poor, $2=$ moderate, $3=$ good \\
$\begin{array}{l}\text { Delivery reliability } \\
\text { - Avg. coverage scale: } 1=\text { limited, } 2=\text { partial, } 3=\text { full }\end{array}$ \\
$\begin{array}{l}\text { Responsiveness } \\
\text { - Avg. monthly order to received days for resource sharing providers }\end{array}$ \\
$\begin{array}{l}\text { Website design for product } \\
\text { information }\end{array}$ & - Avg. monthly query to response days \\
\hline
\end{tabular}

\section{INTERNAL}

\begin{tabular}{|c|c|}
\hline Inventory & $\begin{array}{l}\text { - Avg. collection usage: acquisition to first use days } \\
\text { - Avg. electronic resources usage: \# article requests per month by } \\
\text { joumal/database } \\
\text { - \% of resources in backlog } \\
\text { - Avg. days resources in backlog } \\
\text { - \% of resources missing } \\
\text { - Avg. days resources missing } \\
\text { - } \% \text { of electronic resources not linked } \\
\text { - Avg. days resources not linked }\end{array}$ \\
\hline Totalresource costs & $\begin{array}{l}\text { - Total cost for all physical resources (purchase price + labor cost to } \\
\text { process) } \\
\text { - Total cost for all electronic resources (purchase price + labor cost to } \\
\text { process) }\end{array}$ \\
\hline Quality defects & $\begin{array}{l}\text { - } \% \text { of information resource orders with errors per month } \\
\text { - } \% \text { of vendor payments with errors per month } \\
\text { - } \% \text { of received orders processed with errors per month } \\
\text { - } \% \text { of items catalogued with errors per month } \\
\text { - } \% \text { of items shelved incorrectly per month }\end{array}$ \\
\hline Fill rate reliability & $\begin{array}{l}\text { - } \% \text { of purchase orders filled per month } \\
\text { - } \% \text { of interlibrary loan requests filled per month } \\
\text { - } \% \text { of document delivery requests filled per month }\end{array}$ \\
\hline Responsiveness & $\begin{array}{l}\text { - Avg. monthly (receipt of purchased resources) to (availability to end- } \\
\text { user) days } \\
\text { - Avg. monthly (receipt of interlibrary loans) to (availability to end-user) } \\
\text { days } \\
\text { - Avg. monthly document delivery to end-user days }\end{array}$ \\
\hline
\end{tabular}

\section{USER}

\begin{tabular}{ll}
\hline Assurance & - \% of purchase orders cancelled per month \\
Empathy & - \% of interlibrary loan requests cancelled per month \\
Reliability & - \% of requests for purchase orders per month delivered to user within 3 \\
& weeks \\
& - \%of interlibiary loan requests per month delivered to user within: 24 \\
& - $\%$ our /articles; 1 week/physical items \\
Responsiveness & - Avg. monthly response time for user emails \\
& - Avg. monthly response time for phone calls \\
Tangibles & loan / document delivery \\
\hline
\end{tabular}




\subsection{SUPPLIER PERFORMANCE MEASURE: USER- FRIENDLINESS SCALE (1 = UNFRIENDLY, 2 = INDIFFERENT, 3 = FRIENDLY)}

While the price of information resources is one of the most important factors when libraries select suppliers, other criteria must also be considered. Many library resources are now found in, or with the help of, web-based indexes and databases. While librarians may acknowledge the need for accessibility with regard to their libraries' own web pages, they may not consider this issue when selecting electronic indexes and databases from outside vendors. Usability problems occur when aspects of an interface cause errors for the end user. A user can find an interface element to be problematic for several reasons: the system might be hard to learn, it might take too long for users to perform tasks, it might cause user errors, and it might be unattractive or unpleasing.

When Lied Library users have problems accessing databases or electronic journals, they can report the problem via an online request form or in person at a service point. In late 2011, the Logistics Division staff compiled data regarding the most problematic databases as reported by users. To evaluate the database interfaces, division staff re-created searches in these databases, using information from the user problem reports. If the database had no search problems, it was assumed the problem was due to usability errors. In one example, when a bibliographic database pdf icon was clicked-on, instead of opening the pdf, a "download manager" screen popped up. The user was expected to indicate a format for the name of the pdf and to choose a download location. This screen confused the users. The issue was reported to the vendor, with the vendor replying that the feature could not be turned off. The staff was consequently polled and rated the vendor's performance as "unfriendly." Ultimately, the vendor was forced to fix the problem.

When users cannot easily get to content, they frequently abandon library-provided databases in favor of searching the Internet, which does not provide content from the library's purchased databases. This results in resources that have been purchased but unused, resulting in a high cost-per-use. Prior to the merger of the departments, information databases were selected largely based on price and content. Afterwards, acquisition staffs were involved in assessing the ability of databases to successfully deliv- er content to users. There is competition among distributors of information resource databases, which are some of the most expensive resources purchased by the library. In this example, division staffs were able to leverage the supply chain to achieve changes from the vendor which assured better usability.

\subsection{INTERNAL PERFORMANCE MEASURE: $\%$ OF ELECTRONIC RESOURCES NOT LINKED}

A perennial operations challenge for libraries is managing the volume of incoming materials to be cataloged and processed. These materials, when not processed in a timely manner, create backlogs. Electronic resources find their way into cataloging backlogs when records are not available, when new systems are introduced, or when staff time and expertise isn't available to address the workflow. Staff may not be aware of the extent of the backlog because electronic resources lack a physical presence. In 2005 the Lied Library purchased an electronic book collection of approximately 3,000 titles, to be made available as published. In 2010, less than half of these titles were discoverable through the library's online catalog, thus the percentage of electronic resources not linked was over 50\%. Public Services staff expressed concern over access to this collection, as it was a scientific collection where currency of research was considered critical by faculty, students and other researchers. Subsequently, the records were loaded into the online catalog as they arrived with content, bringing the measure to $100 \%$, increasing the use of the collection significantly.

This problem was used as a case to improve coordination of what was formerly fragmented department work-each function performed its task to internal standards before passing it on to the next function. The supply chain model caused staff to consider their work as part of a chain of processes that ultimately delivered product and services to customers. Staffs collectively agreed that it was better to provide records as quickly as possible, to reduce the number of missed opportunities by users to locate information resources. This was evidenced by the increase in use of the collection after records were loaded. Any issues with record quality could be cleaned up afterward, without creating unnecessary backlogs. 


\subsection{USER PERFORMANCE MEASURE: $\%$ OF INTERLIBRARY LOAN REQUESTS CANCELLED PER MONTH}

Interlibrary loan is intended to serve as a resource for items unobtainable at the local library. Users often submit interlibrary loan requests for items already owned by the library, without realizing the item is already available. Unlike librarians, users are not experts in navigating the complex landscape ofinformation resources, digital repositories, and the organization and classification of library materials. Their desire is simply to obtain information resources to help them complete research and academic assignments. Requests for locally-owned items are a frustration for interlibrary loan staff, as they would rather spend time locating items the library does not actually own. There is a large variation in the way libraries count filled interlibrary loan requests, as some fill the requests for locally available items, while others cancel these requests. Cancelling these requests can lead to user frustration due to the delay in obtaining the requested item, and from the realization they could have had it sooner all along.

During the action research period, a process review of the Lied Interlibrary Loan unit was performed with a consideration of the unit's role in the supply chain. Consequently, $20 \%$ of requests received from library patrons were found to be for items locally owned or accessible. Prior to the development of the supply chain model, the policy was to cancel those requests. After several division staff discussions and discussions with users, the group concluded that customer expectations for an interlibrary loan request were that the request be filled, regardless of the circumstances. Staff decided to connect users with what they sought, no matter the avenue, and further, to set a goal of filling $100 \%$ of the loan requests. The Interlibrary Loan unit implemented a desktop delivery service for articles from UNLV print journals, sent direct links to users for electronic journals, and paged from local collections. These changes resulted in a decrease in the cancelled interlibrary loan requests per month from approximately $30 \%$ to $5 \%$, with some months approaching $0 \%$.

In this example, staff's new understanding of the supply chain created a shift in the level of cooperation between the multiple units in the new division. The work flows of multiple units, including interlibrary loan, book stacks, and circulation had to be co- ordinated so that requests from users passed seamlessly from unit to unit without delay. Previously, requests were either cancelled or handed off to another unit, where they would wait until the previous requests for that unit were completed. With the supply chain perspective, all internal supply chain partners worked to seamlessly move the requests in the order received from start to finish.

\section{CONCLUSIONS}

As the economic and technological climate for academic libraries undergoes dramatic change, few can continue to operate as they traditionally have. User expectations are changing just as rapidly, and libraries need to ensure that a customer orientation drives all activities. This paper presents one solution to accomplishing these imperatives with dwindling resources to remain sustainable.

The departments within Lied Library that were merged had different cultures, acting independently with their own goals and performance metrics. The desired outcome of the merger was to provide better service to users while optimizing the work of the many processes required across the acquisition and delivery of information resources. A different model of work management was required to allow the library to be flexible and responsive to rapidly changing environments. The action research plan of mapping the Lied Library's supply chain provided a unique opportunity to allow the newly formed division's staff to learn about SCM and then apply this new knowledge in guiding the division and the library in general, in a new direction. At the end of the study period, library staff were busy diagnosing and improving performance deficiencies, and were excited to be making genuine progress.

The Lied Library staff is successfully evaluating its supply chain and its ability to provide value to its users in a scarce resource environment. The performance measures in Table I represent the linkages will allow the Lied Library and its suppliers to perform ongoing assessments of how successfully they are providing what their users want. Use of these measures has already allowed several improvementsto be realized. Through this action-based model building exercise, library staff have gained knowledge of the importance of supply chain management and library patrons are beginning to see some results. 
The use of action research to foster the understanding of supply chain management and its valuecreating activities has implications for other applications. Obviously, academic libraries and other public libraries can benefit from this approach, and even make use of the same performance measures. Allowing employees to take an active role in supply chain modeling and performance assessment and improvement creates opportunities for employees to buy-into and support organizational changes and then develop enthusiasm for ongoing improvement activities. Additionally though, action research can be used in any organizational setting where employee support is necessary, with similar results to what has been discussed here. For the Lied Library, future research activities include surveys of library users to more closely tie the library's improvement efforts to user assessments.

\section{REFERENCES}

Association of Research Libraries. "New Measures," found at http://www.arl.org/stats/initiatives/newmeas.shtml (accessed October 17, 2011).

Ball, D.\& Wright, S., "Procuring Electronic Information: New Business Models in the Context of the Supply Chain," Library Consortium Management 2, 7 (2000): 145-154.

Ball, D., "What's the 'Big Deal' and Why is it a Bad Deal for Universities?" Interlending \& Document Supply 32, 2 (2004): 11720.

Boekhorst, P., "Measuring Quality: The IFLA Guidelines for Performance Measurement in Academic Libraries," IFLA Journal 21 (1995): 278-281.

Brondo, K. \& Baba, M., “First In, First Out: A Case Study of Lean Manufacturing's 'Success' in North America's Automobile Industry," Human Organization 69, 3 (2010): 263-274.

Cagliano, R., Caniato, F. \&Spina, G., “The Linkage Between Supply Chain Integration and Manufacturing Improvement Programmes," International Journal of Operations $\mathcal{E}$ Production Management 26, 3/4 (2006): 282-299.

Cho, J., "Developing a SCM-based Evaluation System for the Korean Academic Library Consortium," Libri 60 (2010): 321330.

Christopher, M. Logistics and supply chain management: Strategies for reducing cost and improving service.Financial Times/Prentice-Hall, New York, NY, 1998.
Christopher, M. \&Towill, D., "Supply Chain Migration from Lean and Functional to Agile and Customized," Supply Chain Management 5, 4 (2000): 206-212.

Cope, B., "Making and Moving Books in New Ways, from the Creator to the Consumer," in Digital Book Production and Supply Chain Management, eds. Cope, B. and Mason, D. (Altona Victoria Australia: Common Ground Publishing Pty Ltd, 2001a), 8-9.

Cope, B., "The Future of the Book: from the Creator to the Consumer, in Creator to Consumer in a Digital Age: Australian Book Production in Transition, eds. Cope, B. and Mason, D. (Altona Victoria Australia: Common Ground Publishing Pty Ltd, 2001b), 31.

Cornish, G., "Librarians: Peacemakers in the New Electronic World," Library Management 17, 4 (1996): 30-33.

Curran, K. and Porter, M., "A Primer on Radio Frequency Identification for Libraries," Library Hi Tech 25, 4 (2007): 595-611.

Fawcett, S. and Magnan, G., Achieving World-Class Supply Chain Alignment: Benefits, Barriers, and Bridges, (Center for Advanced Purchasing Studies, Tempe, AZ, 1998).

Fearon, H. and Leenders, M., Purchasing's Organizational Roles and Responsibilities, (Center for Advanced Purchasing Studies, Tempe, AZ, 1996).

Finn, J., "The Promise of Participatory Research, Journal of Progressive HumanServices 5, 2 (1994): 25-42.

Frankel, R.Goldsby, T., and Whipple, J., "Grocery Industries Collaboration in the Wake of ECR," International Journal of Logistics Management 13, 1 (2002): 57-72.

Halley, A.\&Nollet, J., "The Supply Chain: The Weak Link for Some Preferred Suppliers?" Journal of Supply Chain Management 38, 2 (2002): 39-47.

Handfield, R., "US Global Sourcing: Patterns of Development," International Journal of Operations and Production Management 14, 6 (1994): 40-51.

Harwick, T., "Optimal Decision-Making for the Supply Chain," APICS - The Performance Advantage 7, 1 (1997): 42-44.

Heinrich, H. and LaFollette, D., "The Archaeology of Habit: Excavating Past Practices in Technical Services," The Bottom Line 23, 1 (2010): 18-22.Kahn, K.\&Mentzer, J., "Logistics and Interdepartmental Integration," International Journal of Physical Distribution and Logistics Management 26, (1996): 6-14.

Katsirikou, A., "Consortia and Knowledge Management: The Functional Context and an Organizational Model," Library Management 24, 6/7 (2003): 337-347. 
Krause, D. and Scannell, T., "Supplier Development Practices: Product- and Service-based Comparisons," Journal of Supply Chain Management 38, 2 (2002): 13-21.

Lakos, A. \& Phipps, S., "Creating a Culture of Assessment: A Catalyst for Organizational Change," Portal: Libraries and the Academy 4, 3 (2004): 345-361.

Lambert, D., Cooper, M. \&Pagh, J. “Supply Chain Management: Implementation Issues and Research Opportunities," International Journal of Logistics Management 19, 2 (1998): 1-19.

Li, X., "Library as Incubating Space for Innovations: Practices, Trends and Skill Sets," Library Management 27, 6/7 (2006): 370-374.

Lummus, R. \&Vokurka, R., “Defining Supply Chain Management: A Historical Perspective and Practical Guidelines," Industrial Management and Data Systems 99, 1 (1999): 11-17.

MacDuffie, J. \& Helper, S., “Creating Lean Suppliers: Diffusing Lean Production through the Supply Chain," California Management Review 39, 4 (1997): 118-153.

Meng-Xing, H., Chun-Xiao, X. \& Yong, Z., "Supply Chain Management Model for Digital Libraries," The Electronic Library 28, 1 (2010): 29-37.

Metters, R., “Quantifying the Bullwhip Effect in Supply Chains," Journal of Operations Management 15, 2 (1997): 89-100.
Pathak, V. and Pathak, K., "Reconfiguring the Higher Education Value Chain," Management in Education 24, 4 (2010): 166-171.

Reason, P. \& Bradbury, H., (Ed.) The SAGE Handbook of Action Research. Participative Inquiry and Practice (Sage Press, London, UK, 2001).

Shapiro, J.,Singhal, V. \& Wagner, S., "Optimizing the Value Chain," Interfaces 23, 2 (1993): 102-117.

Smeltzer, L. and Ogden, J., "Purchasing Professionals' Perceived Differences Between Purchasing Materials and Purchasing Services," Journal of Supply Chain Management 38, 1 (2002): 54-70.

Spekman, R., Kamauff, J.\&Myhr, N., “An Empirical Investigation into Supply Chain Management," International Journal of Physical Distribution and Logistics Management 28, 8 (1998): 630-650.

Spens, Karen M. and Bask, Anu H., "Developing a Framework for Supply Chain Management," International Journal of Logistics Management 13, 1 (2002): 73-88.

Stank, T., Goldsby, T., Vickery, S.,\&Savitskie, K., “Logistics Service Performance: Estimating its Influence on Market Share," Journal ofBusiness Logistics 24, 1 (2003): 27-56.

Womack, J. \& Jones, D., Lean Thinking (The Free Press, New York, NY, 2003), 16-19.

\section{AUTHOR'S BIOGRAPHY}

Nancy Kress is currently Head of Access and Delivery Services with North Carolina State University Libraries, where she is responsible for management of services associated with the borrowing, lending and storage of library materials. She has eight years of practical experience applying Lean and business process improvement methods in higher education. Her publications include applying Lean and quality improvement methods in academic environments, and she has presented on Lean and process improvement at national library conferences.

Joel Wisner earned his Ph.D. in Supply Chain Management from Arizona State University in 1991. He is currently professor of supply chain management at the University of Nevada, Las Vegas. He has written two supply chain management textbooks, one of which enjoys a wide distribution among many universities (Principles of Supply Chain Management 3rd ed., South-western Cengage, 2012). His 40-plus publications have appeared in numerous journals including Journal of Business Logistics, Journal of Operations Management, Journal of Supply Chain Management, Journal of Transportation, Production and Operations Management Journal, and Quality Management Journal. 